\title{
Propiedades físico-químicas y digestibilidad in vitro de mezclas alimenticias de cultivos andinos y cereales extruidos
}

Physico-chemical properties and in vitro digestibility of a food mixture of Andean crops and cereals extruded

Propriedades físico-químicas e digestibilidade in vitro de uma mistura alimentícia de cultivos andinos e cereais extrusados

\author{
Elizabeth Huanatico-Suárez ${ }^{1}$ \\ ehuanatico@unaj.edu.pe \\ https://orcid.org/0000-0003-2981-588X
}

\author{
Adaliht Jhony Arisaca-Parillo ${ }^{2}$ \\ aj.arisaca@unaj.edu.pe \\ https://orcid.org/0000-0003-4931-8290
}

Alberto Quispe
roder.erick@gmail.com
https://orcid.org/0000-0002-2109-040X

\author{
Miriam Calla Florez ${ }^{1}$ \\ miriamcalla@yahoo.es \\ https://orcid.org/0000-0003-0592-6454
}

\author{
Percy Zavaleta Huampa ${ }^{2}$ \\ zavaleta2474@gmail.com \\ https://orcid.org/0000-0002-2689-7237
}

\author{
Edgar Alcides Quispe Callo \\ walon144@gmail.com \\ https://orcid.org/0000-0001-6711-4086
}

${ }^{1}$ Universidad Nacional de Juliaca, Juliaca-Puno-Perú

${ }^{2}$ Universidad Nacional San Antonio Abad del Cusco, Cusco-Perú

Artículo recibido 10 de octubre 2021 / Arbitrado y aceptado 15 de noviembre 2021 / Publicado 13 de diciembre 2021

\section{RESUMEN}

El objetivo de la investigación fue formular una mezcla alimenticia a base de quinua, maca, cebada y arroz destinada a adultos mayores de acuerdo a las especificaciones de productos instantáneos. Asimismo, se determinó el efecto de cocción extrusión en las propiedades físico-químicas y digestibilidad in vitro de las mezclas seleccionadas. Para obtener la mejor formulación se utilizó el score de aminoácidos obteniendo 25 mezclas y que evaluadas por su calidad proteica, se tomaron 03 muestras, sometiéndose a un proceso de cocción por extrusión con una temperatura entre $140 \mathrm{y}$ $165^{\circ} \mathrm{C}$ y una humedad inicial entre 10 y $15 \%$, obteniéndose productos extruidos con un índice de gelatinización entre 94.34 a $95.87 \%$, 0.98 a 1.15 a meq/kg para el índice de peróxidos, valor proteico entre 7.4 y $10.33 \%$, y entre 1.54 y 1.73 $\%$ de fibra. La digestibilidad in vitro presentó valores entre 67.0 y 86.00 . Se concluye que la mezcla óptima de acuerdo a los parámetros evaluados es la mezcla 3 compuesta por 30 $\%$ de maca, $25 \%$ quinua, $35 \%$ cebada y 10 $\%$ de arroz con un índice de gelatinización de $95.87 \%$, índice de peróxidos $0.98 \mathrm{meq} / \mathrm{kg}$, Digestibilidad in vitro de $86 \%$, proteína $7.4 \%$, fibra $1.54 \%$, grasa $2.5 \%$, las propiedades físicoquímicas fueron influenciadas por la humedad inicial (10 y $15 \%)$ y temperatura (160 - 165 $\left.{ }^{\circ} \mathrm{C}\right)$, en cuanto al análisis microbiológico de la mezcla seleccionada están dentro de los límites establecidos por la normativa vigente.

Palabras clave: Harina; Índice de gelatinización; Índice de peróxidos; Proteínas; Score químico
ABSTRACT

The aim of the research was to formulate a food mixture based on quinoa, maca, barley and rice for adults according to the specifications of instant products. Likewise, the effect of extrusion cooking on the physicochemical properties and in vitro digestibility of the selected selections was determined. To obtain the best formulation, the amino acid score was used, getting 25 mixtures and, evaluated for their protein quality, 03 samples were taken, undergoing a process of extrusion cooking with a temperature between 140 and $165^{\circ} \mathrm{C}$ and an initial humidity between 10 and $15 \%$, obtaining extruded products with a gelatinization index between 94.34 and $95.87 \%, 0.98$ to 1.15 a $\mathrm{meq} / \mathrm{kg}$ for the peroxide index, protein value between 7.4 and $10.33 \%$, and between 1.54 and $1.73 \%$ of fiber. In vitro digestibility presented values between 67.0 and 86.00 . It is concluded that the optimal mixture according to the evaluated parameters is mixture 3 for $30 \%$ maca, $25 \%$ quinoa, $35 \%$ barley and $10 \%$ rice with a gelatinization index of $95.87 \%$, peroxide index $0.98 \mathrm{meq} / \mathrm{kg}$, In vitro digestibility of $86 \%$, protein $7.4 \%$, fiber $1.54 \%$, fat $2.5 \%$, the physicalchemical properties were influenced by the initial humidity (10 and $15 \%$ ) and temperature $\left(160-165^{\circ} \mathrm{C}\right)$, regarding the Microbiological analysis of the selected mixture is within the limits established by current regulations.

Key words: Flour; Gelatinization index; Peroxide index; Proteins; Chemical score

\section{RESUMO}

O objetivo da pesquisa foi formular uma mistura alimentar à base de quinoa, maca, cevada e arroz para idosos de acordo com as especificações dos produtos instantâneos. Da mesma forma, foi determinado o efeito do cozimento por extrusão nas propriedades físico-químicas e na digestibilidade in vitro das misturas selecionadas. Para obter a melhor formulação, utilizou-se o escore de aminoácidos, obtendo-se 25 misturas e, avaliadas quanto à qualidade protéica, foram retiradas 03 amostras, submetidas a um processo de cozimento por extrusão com temperatura entre 140 e $165^{\circ} \mathrm{C}$ e umidade inicial entre 10 e $15 \%$, obtendo produtos extrusados com índice de gelatinização entre 94,34 e $95,87 \%, 0,98$ a 1,15 a meq / kg para o índice de peróxidos, valor de proteína entre 7,4 e $10,33 \%$ e entre 1,54 e $1,73 \%$ de fibra. A digestibilidade in vitro apresentou valores entre 67,0 e 86,00 . Conclui-se que a mistura ótima de acordo com os parâmetros avaliados é a mistura 3 composta por $30 \%$ de maca, $25 \%$ de quinua, $35 \%$ de cevada e $10 \%$ de arroz com índice de gelatinização de $95,87 \%$, índice de peróxido de 0,98 meq / kg, digestibilidade in vitro de $86 \%$, proteína $7,4 \%$, fibra $1,54 \%$, gordura $2,5 \%$, as propriedades físico-químicas foram influenciadas pela umidade inicial (10 e 15\%) e temperatura (160 - $\left.165^{\circ} \mathrm{C}\right)$, tanto quanto $\mathrm{A}$ análise microbiológica de a mistura selecionada está dentro dos limites estabelecidos pela regulamentação em vigor.

Palavras-chave: Farinha; Índice de gelatinização; Índice de peróxidos; Proteínas; Pontuação química 


\section{INTRODUCCIÓN}

La industria alimentaria busca continuamente la mejora en el diseño y la eficiencia de los procesos a fin de facilitar el desarrollo de nuevos productos acordes a las necesidades de los consumidores; es así, que el aumento de la esperanza de vida en la población ha hecho que los adultos mayores busquen alimentos saludables, de fácil preparación y acorde a sus necesidades ya que las personas de ese grupo etario presentan problemas dentales, masticación, reducción de la tasa metabólica y absorción de nutrientes (1), estos factores de la edad avanzada traen consigo la pérdida de peso, masa muscular, fuerza o reservas fisiológicas esenciales (2), los cuales repercuten en la longevidad, calidad de vida y mejora nutricional.

Las estimaciones de la población mayor de 65 años para el año 2050 asciende a 1.5 mil millones, el cual representará $16 \%$ de la población mundial, superando la cantidad de adolescentes y jóvenes de entre 15 y 24 años, además se espera que la esperanza de vida pase de 72.6 años en promedio a 77.1 años para el año 2050 según las Naciones Unidas, Departamento de Asuntos Económicos y Sociales, División de Población. En ese entender, existe campo de acción promisorio para la formulación y diseño de mezclas alimenticias de alto valor nutritivo y acorde a las necesidades de los grupos etarios.

El desarrollo de nuevos productos a partir de mezclas alimenticias permite la aplicación de tecnologías versátiles como el caso de la cocción extrusión, dicha operación involucra altas temperaturas (HTST) y presión (3), asimismo, se debe considerar la humedad del alimento, ya que tienen un efecto en las propiedades del producto, y digestibilidad de las proteínas (4), además de esterilizar el producto y desnaturalizar las enzimas indeseables como los inhibidores de tripsina, taninos y fitatos (5). En la extrusión de alimentos el alimento fluye bajo una variedad de condiciones de mezclado, calentamiento, cocción y cizallamiento (6;7), además del moldeado (8).

Los alimentos que más fácil se han adaptado al proceso de extrusión son los cereales, principalmente por su contenido de almidón, éste compuesto es responsable de la expansión (9), y en el caso de los granos andinos por sus características nutricionales que se complementan a la hora de formular mezclas alimenticias, además de ser de fácil acceso y gran aceptabilidad por parte de los consumidores, aprovechando con ello los recursos alimentarios disponibles del país. De los insumos utilizados la quinua presenta un alto contenido de proteínas, principalmente albúminas y globulinas, de excelente balance de aminoácidos (10), la maca contiene en su composición proteínas, fibra, minerales como el hierro, lípidos, ácidos grasos (11), metabolitos secundarios como los glucosinolatos (12), ácidos grasos, esteroles, y polifenoles (13). Por su parte la cebada presenta proteínas, hidratos de carbono, pero baja en grasas (14). El arroz contiene vitaminas, minerales, compuestos fenólicos, ácidos grasos, entre otros (15). La combinación y formulación de 
la quinua, maca, cebada y arroz, a través del score químico, permitirá conocer el efecto de la cocción por extrusión sobre las propiedades físico-químicas y digestibilidad in vitro, acorde a los requisitos establecidos para alimentos instantáneos.

\section{MATERIALES Y MÉTODOS}

\section{Materia prima y su acondicionamiento}

Se adquirió granos de quinua (Variedad Amarilla Maranganí), maca (ecotipo amarillo), cebada y arroz pilado de la empresa Argos Export S.A. posteriormente se obtuvo gritz a partir de maca, cebada y arroz, y en el caso de la quinua fue desaponificada utilizando el método combinado para obtener quinua perlada.

\section{Score de aminoácidos}

Se formularon mezclas empleando proporciones variadas de quinua, maca, cebada y arroz, expresadas en base seca, con el uso de algoritmos a fin de minimizar la diferencia entre la concentración de aminoácidos de la referencia, a través del método Score o Cómputo químico recomendado por la FAO/ OMS/UNU (16) y Pellet y Vernon (17).

\section{Cómputo químico \\ $=\frac{m g \text { de aminoácido en } 1 \mathrm{~g} \text { de nitrógeno de la proteína de la mezcla }}{m g \text { de aminoácido en } 1 \mathrm{~g} \text { de nitrógeno de la proteína de referencia }} \times 100$}

\section{Proceso de extrusión}

La cocción por extrusión de las tres mezclas seleccionadas (Tabla 1), se llevó a cabo en una extrusora de tornillo simple modelo G\&M con una capacidad de $20 \mathrm{~kg} / \mathrm{h}$ de acero inoxidable. Las muestras extruidas fueron acondicionadas a diferente humedad inicial de 10 a $15 \%$ y niveles de temperatura entre $140^{\circ}$ y $165^{\circ} \mathrm{C}$ por un espacio de tiempo entre 4 y 9 segundos. Una vez extruidas las tres mezclas, se sometieron a molienda utilizando un molino de martillos modelo Innova con capacidad de $60 \mathrm{~kg} / \mathrm{h}$ de acero inoxidable y almacenarlo en bolsones de polietileno de alta densidad (PEAD) de 0.940 $\mathrm{gr} / \mathrm{cm} 2$ y polipropileno biorientado (BOPP) de $0.60 \mathrm{gr} / \mathrm{cm} 2$, de acuerdo a las recomendaciones del Codex Stan (18). 
Tabla 1. Muestras seleccionadas.

\begin{tabular}{ccc}
\hline Mezcla & Tratamiento y temperatura de extrusión & Formulación \\
\hline & & \\
$M-1$ & $T 1\left[140^{\circ} \mathrm{C}-145^{\circ} \mathrm{C}\right]$ & $\mathrm{M}=10 \%, \mathrm{Q}=25 \%, \mathrm{C}=20 \%, \mathrm{~A}=45 \%$ \\
& $\mathrm{~T} 2\left[150^{\circ} \mathrm{C}-155^{\circ} \mathrm{C}\right]$ & $\mathrm{M}=10 \%, \mathrm{Q}=25 \%, \mathrm{C}=20 \%, \mathrm{~A}=45 \%$ \\
& $\mathrm{~T} 3\left[160^{\circ} \mathrm{C}-165^{\circ} \mathrm{C}\right]$ & $\mathrm{M}=10 \%, \mathrm{Q}=25 \%, \mathrm{C}=20 \%, \mathrm{~A}=45 \%$ \\
& & \\
$\mathrm{~T} 4\left[140^{\circ} \mathrm{C}-145^{\circ} \mathrm{C}\right]$ & $\mathrm{M}=20 \%, \mathrm{Q}=30 \%, \mathrm{C}=20 \%, \mathrm{~A}=30 \%$ \\
$\mathrm{~T}-2$ & $\mathrm{~T} 5\left[150^{\circ} \mathrm{C}-155^{\circ} \mathrm{C}\right]$ & $\mathrm{M}=20 \%, \mathrm{Q}=30 \%, \mathrm{C}=20 \%, \mathrm{~A}=30 \%$ \\
& $\mathrm{~T} 6\left[160^{\circ} \mathrm{C}-165^{\circ} \mathrm{C}\right]$ & $\mathrm{M}=20 \%, \mathrm{Q}=30 \%, \mathrm{C}=20 \%, \mathrm{~A}=30 \%$ \\
$\mathrm{~T}-3$ & $\mathrm{~T} 7\left[140^{\circ} \mathrm{C}-145^{\circ} \mathrm{C}\right]$ & $\mathrm{M}=30 \%, \mathrm{Q}=25 \%, \mathrm{C}=35 \%, \mathrm{~A}=10 \%$ \\
& $\mathrm{~T} 8\left[150^{\circ} \mathrm{C}-155^{\circ} \mathrm{C}\right]$ & $\mathrm{M}=30 \%, \mathrm{Q}=25 \%, \mathrm{C}=35 \%, \mathrm{~A}=10 \%$ \\
& $\mathrm{~T} 9\left[160^{\circ} \mathrm{C}-165^{\circ} \mathrm{C}\right]$ & $\mathrm{M}=30 \%, \mathrm{Q}=25 \%, \mathrm{C}=35 \%, A=10 \%$ \\
\hline
\end{tabular}

\section{Análisis físico-químico}

Se analizó la humedad por el método NTP 206.011, proteína total (A.O.A.C. 935.39C), grasa cruda mediante el método NTP206.017, cenizas (A.O.A.C. 935.39B), fibra cruda (FAO 14/7). Además, se determinó el índice de peróxidos durante el almacenamiento a fin medir el nivel de oxidación lipídica a temperatura ambiente según la metodología descrita por NTP 206.016, e índice de gelatinización mediante CERPER LE-ME-IG.

\section{Digestibilidad in vitro}

El porcentaje de nitrógeno asimilado de la mezcla estudiada se determinó por el método A.O.A.C. 971.09 que nos da valores aproximados de la absorción de proteína ingerida por el organismo, utilizando para ello una solución multienzimática a un $\mathrm{pH}$ de 6.8 , y posteriormente se empleó el método Kjeldahl descrito por A.O.A.C. (19), para determinar la proteína total en el residuo sólido.

\section{RESULTADOS Y DISCUSIÓN}

\section{Formulación de la mezcla}

Serealizóelcálculodelscoredeaminoácidos o cómputo químico de las mezclas utilizado los aminogramas de cada componente. Los aminoácidos considerados fueron basados de acuerdo a las recomendaciones de la FAO/ OMS (20), teniendo presente el cálculo del aminoácido limitante.

De las 25 mezclas formuladas, se seleccionó 03 (Tabla 2) con $25 \%$ de quinua, $35 \%$ de cebada, $30 \%$ de maca y $10 \%$ arroz, por presentar un valor superior al 70\% del patrón. 
Tabla 2. Formulaciones seleccionadas a partir del score de aminoácidos de la mezcla alimenticia.

\begin{tabular}{|c|c|c|c|c|c|c|c|c|c|c|c|c|c|}
\hline \multirow{2}{*}{ 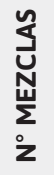 } & \multicolumn{4}{|c|}{ FORMULACIONES (\%) } & \multicolumn{9}{|c|}{ AMINOÁCIDOS (mg aa/mezcla) } \\
\hline & C & $\mathbf{Q}$ & $\mathbf{M}$ & A & Histidina & Isoleucina & Leucina & Lisina & $\begin{array}{c}\text { Treonina } \\
+ \\
\text { Cisteína }\end{array}$ & $\begin{array}{c}\text { Fenil. } \\
+ \\
\text { Tirosina }\end{array}$ & Treonina & Triptófano & Valina \\
\hline 1 & 20 & 25 & 10 & 45 & 153.18 & 310.80 & 376.71 & 267.06 & 133.73 & 285.84 & 374.11 & 229.80 & 421.57 \\
\hline 2 & 20 & 30 & 20 & 30 & 153.75 & 311.15 & 358.47 & 284.12 & 135.82 & 299.78 & 367.77 & 206.80 & 421.46 \\
\hline 3 & 35 & 25 & 30 & 10 & 150.03 & 309.53 & 340.78 & 290.87 & 135.02 & 321.86 & 365.11 & 198.40 & 422.03 \\
\hline
\end{tabular}

\section{Composición físico-químico de la mezcla extruida}

\section{Determinación del índice de gelatinización}

En la Tabla 3, se muestra los tres tratamientos de la mezcla instantánea a base de quinua, maca, cebada y arroz, presenta altos valores funcionales en cuanto al índice de gelatinización con un porcentaje promedio de $95 \%$.

Tabla 3. Índice de Gelatinización.

\begin{tabular}{ccc}
\hline Mezcla & Tratamiento & Índice de gelatinización (\%) \\
\hline & $\mathrm{T} 1\left[140^{\circ} \mathrm{C}-145^{\circ} \mathrm{C}\right]$ & $94.34 \pm 0.02$ \\
$\mathrm{M}-1$ & $\mathrm{~T} 2\left[150^{\circ} \mathrm{C}-155^{\circ} \mathrm{C}\right]$ & $94.51 \pm 0.16$ \\
& $\mathrm{~T} 3\left[160^{\circ} \mathrm{C}-165^{\circ} \mathrm{C}\right]$ & $95.00 \pm 0.10$ \\
& $\mathrm{~T} 4\left[140^{\circ} \mathrm{C}-145^{\circ} \mathrm{C}\right]$ & $94.51 \pm 0.45$ \\
$\mathrm{M}-2$ & $\mathrm{~T} 5\left[150^{\circ} \mathrm{C}-155^{\circ} \mathrm{C}\right]$ & $94.91 \pm 0.20$ \\
& $\mathrm{~T} 6\left[160^{\circ} \mathrm{C}-165^{\circ} \mathrm{C}\right]$ & $95.50 \pm 0.04$ \\
& $\mathrm{~T} 7\left[140^{\circ} \mathrm{C}-145^{\circ} \mathrm{C}\right]$ & $94.99 \pm 0.03$ \\
$\mathrm{M}-3$ & $\mathrm{~T} 8\left[150^{\circ} \mathrm{C}-155^{\circ} \mathrm{C}\right]$ & $95.50 \pm 0.02$ \\
& $\mathrm{~T} 9\left[160^{\circ} \mathrm{C}-165^{\circ} \mathrm{C}\right]$ & $95.87 \pm 0.03$ \\
\hline
\end{tabular}

En la Figura 1, se aprecia la variación del índice de gelatinización con respecto a la temperatura, que cuanto más alta sea la temperatura, el índice de gelatinización es mayor, siendo la mezcla 3 con mayor índice de gelatinización con $95.45 \%$, respecto a las mezclas 1 y 2 . 


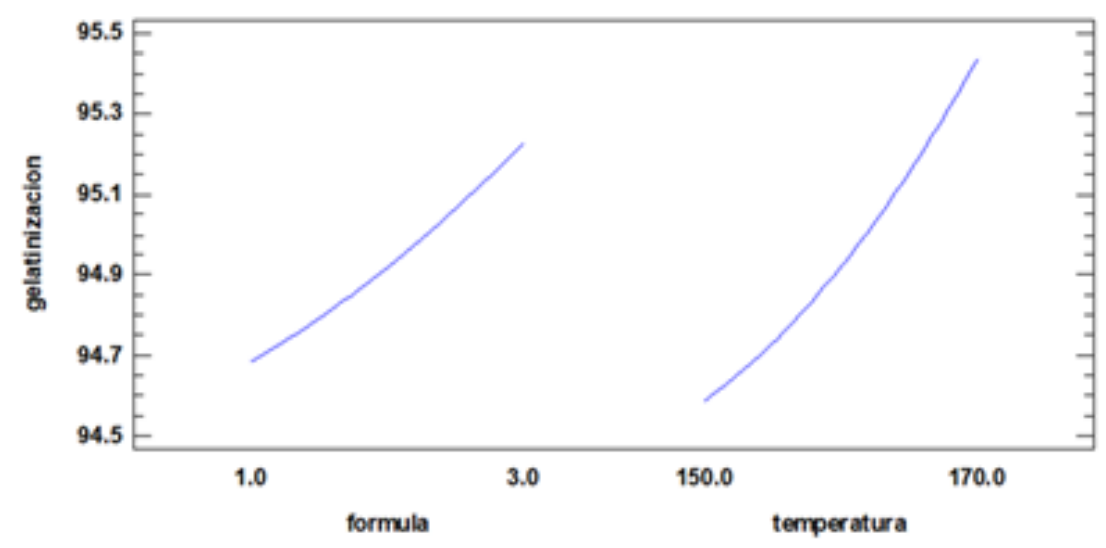

Figura 1. Índice de gelatinización en las tres mezclas alimenticias.

\section{Determinación del índice de peróxidos}

En la Tabla 4, se presenta los resultados del índice de peróxidos de las tres mezclas seleccionadas.

Tabla 4. Índice de peróxidos de las tres mezclas alimenticias.

\begin{tabular}{ccc}
\hline Mezcla & Tratamiento & Índice de peróxidos (meq/Kg) \\
\hline & $\mathrm{T} 1\left[140^{\circ} \mathrm{C}-145^{\circ} \mathrm{C}\right]$ & $1.10 \pm 0.17$ \\
$\mathrm{M}-1$ & $\mathrm{~T} 2\left[150^{\circ} \mathrm{C}-155^{\circ} \mathrm{C}\right]$ & $1.14 \pm 0.16$ \\
& $\mathrm{~T} 3\left[160^{\circ} \mathrm{C}-165^{\circ} \mathrm{C}\right]$ & $1.10 \pm 0.12$ \\
& $\mathrm{~T} 4\left[140^{\circ} \mathrm{C}-145^{\circ} \mathrm{C}\right]$ & $0.90 \pm 0.08$ \\
$\mathrm{M}-2$ & $\mathrm{~T} 5\left[150^{\circ} \mathrm{C}-155^{\circ} \mathrm{C}\right]$ & $1.15 \pm 0.23$ \\
& $\mathrm{~T} 6\left[160^{\circ} \mathrm{C}-165^{\circ} \mathrm{C}\right]$ & $1.12 \pm 0.05$ \\
& $\mathrm{~T} 7\left[140^{\circ} \mathrm{C}-145^{\circ} \mathrm{C}\right]$ & $1.06 \pm 0.19$ \\
$\mathrm{M}-3$ & $\mathrm{~T} 8\left[150^{\circ} \mathrm{C}-155^{\circ} \mathrm{C}\right]$ & $1.12 \pm 0.14$ \\
& $\mathrm{~T} 9\left[160^{\circ} \mathrm{C}-165^{\circ} \mathrm{C}\right]$ & $0.98 \pm 0.16$ \\
\hline
\end{tabular}

En la Figura 2, se observa que la mezcla 3 es la que presenta menor cantidad de oxidación de lípidos con $1.05 \mathrm{meq} / \mathrm{Kg}$ en promedio, a una temperatura que varía entre 160 y $165^{\circ} \mathrm{C}$ con respecto a la primera mezcla que presenta un índice de peróxido de $1.11 \mathrm{meq} / \mathrm{Kg}$, encontrándose una diferencia proporcional entre ambas mezclas, habiendo menos tendencia a sufrir oxidación de lípidos en su composición. 


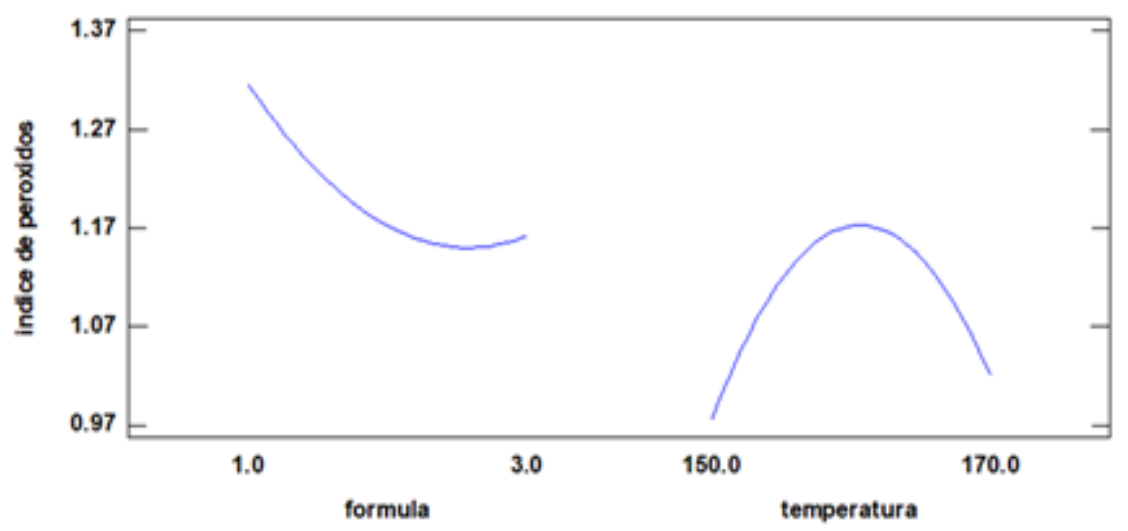

Figura 2. Índice de peróxidos en las tres mezclas alimenticias.

\section{Análisis químico proximal}

En la Tabla 5, se puede apreciar los resultados del análisis proximal de las tres mezclas seleccionadas a partir de quinua, maca, cebada y arroz; se observa que conforme incrementa la temperatura el grado de humedad disminuye, encontrándose una diferencia proporcional entre las mezclas. La humedad media es de $4.14 \%$, este valor está dentro de los criterios fisicoquímicos de implicancia sanitaria establecidos para alimentos cocidos de reconstitución instantánea (menor o igual a 5\%).

Tabla 5. Composición químico proximal de las tres mezclas alimenticias.

\begin{tabular}{ccccccc}
\hline $\begin{array}{c}\text { Mezcla / } \\
\text { Tratamiento }\end{array}$ & Humedad & Proteínas & Grasa & Ceniza & Fibra & Carbohidratos \\
\hline$M-1 / 1$ & $4.45 \pm 0.01$ & $10.33 \pm 0.10$ & $3.92 \pm 0.09$ & $1.82 \pm 0.01$ & $1.73 \pm 0.08$ & $79.57 \pm 0.06$ \\
$M-1 / 2$ & $4.21 \pm 0.04$ & $9.08 \pm 0.08$ & $3.42 \pm 0.13$ & $1.69 \pm 0.02$ & $1.71 \pm 0.04$ & $81.58 \pm 0.04$ \\
$M-1 / 3$ & $4.14 \pm 0.06$ & $7.49 \pm 0.07$ & $3.42 \pm 0.03$ & $1.75 \pm 0.02$ & $1.65 \pm 0.02$ & $83.20 \pm 0.19$ \\
$M-2 / 1$ & $4.22 \pm 0.22$ & $9.9 \pm 0.22$ & $3.4 \pm 0.11$ & $1.62 \pm 0.01$ & $1.68 \pm 0.07$ & $79.86 \pm 0.17$ \\
$M-2 / 2$ & $4.18 \pm 0.03$ & $8.52 \pm 0.03$ & $3.41 \pm 0.14$ & $1.45 \pm 0.03$ & $1.68 \pm 0.06$ & $82.21 \pm 0.10$ \\
$M-2 / 3$ & $4.02 \pm 0.14$ & $7.43 \pm 0.06$ & $3.39 \pm 0.03$ & $1.65 \pm 0.02$ & $1.64 \pm 0.03$ & $83.52 \pm 0.01$ \\
$M-3 / 1$ & $4.2 \pm 0.01$ & $9.15 \pm 0.11$ & $3.68 \pm 0.02$ & $1.4 \pm 0.01$ & $1.7 \pm 0.01$ & $81.27 \pm 0.20$ \\
$M-3 / 2$ & $4.02 \pm 0.03$ & $7.43 \pm 0.05$ & $3.39 \pm 0.01$ & $1.45 \pm 0.01$ & $1.64 \pm 0.02$ & $83.52 \pm 0.08$ \\
$M-3 / 3$ & $4.01 \pm 0.03$ & $7.4 \pm 0.07$ & $2.5 \pm 0.34$ & $1.41 \pm 0.01$ & $1.54 \pm 0.06$ & $84.55 \pm 0.12$ \\
\hline
\end{tabular}

\section{Digestibilidad in vitro}

Los resultados se presentan en la Tabla 6 y Figura 3, se muestra que conforme la temperatura incrementa, la digestibilidad aumenta observándose que la media de la mezcla 3 (86.00\%), es superior a la mezcla $1(76.00 \%)$ y $2(79.00 \%)$. 
Tabla 6. Digestibilidad in vitro de las tres mezclas alimenticias.

\begin{tabular}{ccc}
\hline Mezcla & Tratamiento & Digestibilidad de proteína (\%) \\
\hline & $\mathrm{T} 1\left[140^{\circ} \mathrm{C}-145^{\circ} \mathrm{C}\right]$ & $67.00 \pm 0.09$ \\
$\mathrm{M}-1$ & $\mathrm{~T} 2\left[150^{\circ} \mathrm{C}-155^{\circ} \mathrm{C}\right]$ & $71.00 \pm 1.00$ \\
& $\mathrm{~T} 3\left[160^{\circ} \mathrm{C}-165^{\circ} \mathrm{C}\right]$ & $76.00 \pm 0.05$ \\
& $\mathrm{~T} 4\left[140^{\circ} \mathrm{C}-145^{\circ} \mathrm{C}\right]$ & $67.00 \pm 0.04$ \\
$\mathrm{M}-2$ & $\mathrm{~T} 5\left[150^{\circ} \mathrm{C}-155^{\circ} \mathrm{C}\right]$ & $72.00 \pm 0.08$ \\
& $\mathrm{~T} 6\left[160^{\circ} \mathrm{C}-165^{\circ} \mathrm{C}\right]$ & $79.00 \pm 0.07$ \\
& $\mathrm{~T} 7\left[140^{\circ} \mathrm{C}-145^{\circ} \mathrm{C}\right]$ & $70.68 \pm 0.03$ \\
& $\mathrm{~T} 8\left[150^{\circ} \mathrm{C}-155^{\circ} \mathrm{C}\right]$ & $79.00 \pm 0.03$ \\
$\mathrm{M}-3$ & $\mathrm{~T} 9\left[160^{\circ} \mathrm{C}-165^{\circ} \mathrm{C}\right]$ & $86.00 \pm 0.05$ \\
\hline
\end{tabular}

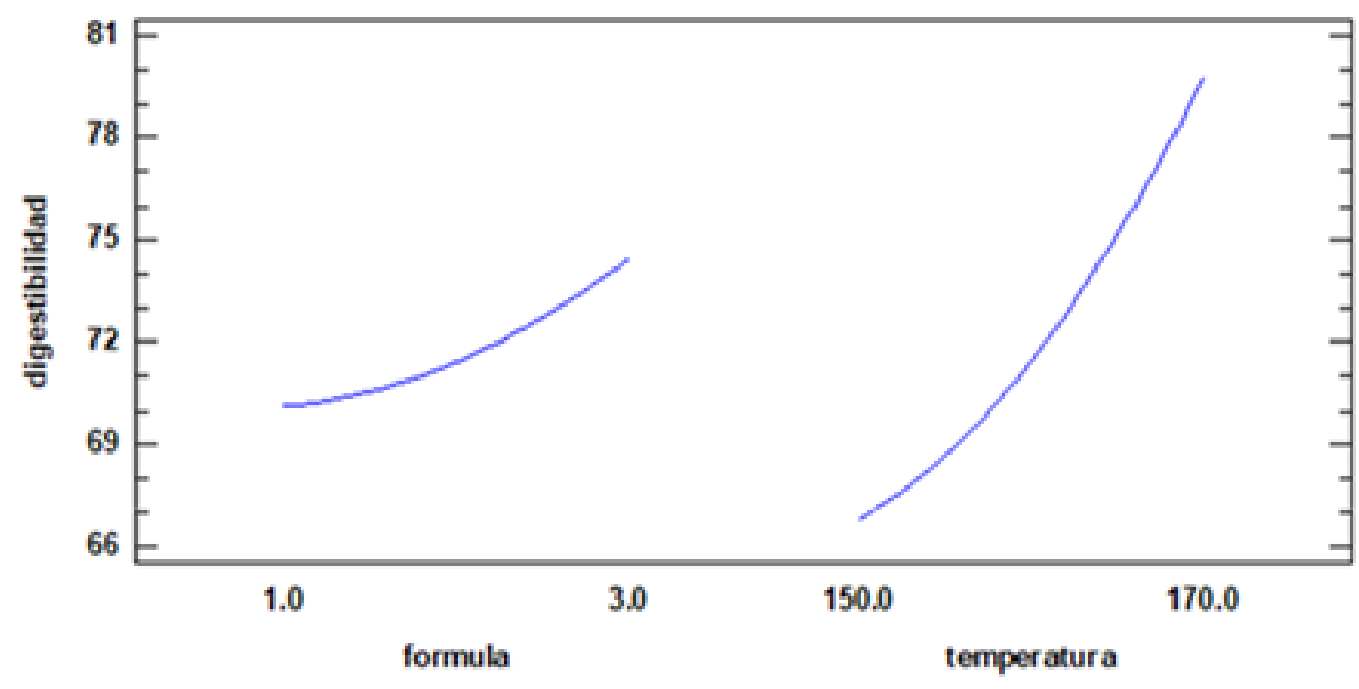

Figura 3. Digestibilidad in vitro en las tres mezclas alimenticias.

\section{Análisis microbiológico}

Los resultados presentados en la Tabla 7, denotan que la muestra seleccionada presenta menores unidades formadoras de colonias (ufc/g) con respecto a los coliformes, levaduras y Bacillus, y ausencia de salmonella y límites por debajo de $105 \mathrm{~g} / \mathrm{ml}$ de mohos y levaduras. 
Tabla 7. Análisis microbiológico de la mezcla seleccionada (M3-T9).

\begin{tabular}{llll}
\hline \multicolumn{1}{c}{ Pruebas } & & Unidad & Resultados \\
N. aerobios mesófilos & ufc/g & 15 & \\
N. Coliformes totales & $\mathrm{NMP} / \mathrm{g}$ & $<3$ & $<100$ \\
N. Bacillus cereus & ufc/g & 15 \\
N. Mohos & ufc/g & $<10$ \\
N. Levaduras & ufc/g & Ausente \\
D. Salmonella & $\mathrm{sp} / 25 \mathrm{~g}$ & & \\
\hline
\end{tabular}

\section{Discusión}

La composición físico-química de la mezcla extruida a base de quinua, maca, cebada y arroz presenta altos valores funcionales con 95\% de índice de gelatinización, esto se debe al proceso de cocción - extrusión, ya que los gránulos de almidón fueron gelatinizados al estar sometidos a una elevada temperatura y humedad, este comportamiento varía, de acuerdo a las distintas proporciones de amilosa y de amilopectina (21). Además, el valor hallado es un indicativo del grado de digestión que tendrá el alimento una vez que sea consumido (22). El valor encontrado, está dentro de los requisitos establecidos en la NTP 011.4572016 (23) con un índice de gelatinización mayor o igual a $85 \%$ y mayor a $94 \%$ establecido dentro de los criterios físico-químicos de implicancia sanitaria para alimentos cocidos de reconstitución instantánea refrendado en la R.M. N 451-2006/MINSA (24).

En cuanto el índice de peróxidos de las tres mezclas seleccionadas presentan 1.07 en promedio, este valor está dentro de los parámetros establecidos por la norma sanitaria para la fabricación de alimentos a base de granos y otros para reconstitución instantánea, en donde se recomienda un valor menor de $10 \mathrm{mEq} / \mathrm{Kg}$ de grasa, además es inferior las recomendaciones físico-químicas de la NTP 011.457-2016 con $10 \mathrm{mEq} / \mathrm{kg}$ de grasa y el Codex Alimentarius (25), que recomienda un máximo de índice de peróxido para aceites entre 5 a $10 \mathrm{mEq} / \mathrm{Kg}$. Este valor inicial después del proceso de extruido, se debe a un proceso natural de enranciamiento con el tiempo, que traen consigo cambios en las propiedades organolépticas, principalmente en el olor, a través de la exposición del oxígeno del aire, presencia de luz y contacto con materiales prooxidantes.

La proteína presente en la mezcla tiene un promedio de $8.53 \%$, éste valor es superior al recomendado por la FAO/OMS (20) con $5.5 \%$ para mezclas alimenticias por cocción extrusión, asimismo, este valor está dentro de las recomendaciones de ingesta entre 0.8 a 1.2 g de proteína/kg de peso corporal/ día para adultos mayores $(26 ; 27)$ y de 1.2 a $1.5 \mathrm{~g}$ de proteína/kg de peso corporal/día para adultos mayores con enfermedad (26), algunos estudios mencionan que la ingesta de $1 \mathrm{~g} / \mathrm{kg}$ podría favorecer un mejor balance de nitrogenado, estimulando la formación de 
masa muscular según la American Dietetic Association y Dietitians of Canada (28).

A partir de los resultados del contenido proteico, seobservaqueconformeseincrementa la temperatura existe una desnaturalización, debido a la perdida y la estructura secundaria y terciaria de la proteína, sin perder la función biológica (21). Por otro lado, se observa que el contenido de fibra es de $1.66 \%$, variando conforme va incrementándose la temperatura, existiendo una diferencia significativa entre la mezcla $1(1.70 \%)$ y $3(1.63 \%)$ respectivamente, esto se debe a que en el proceso de extrusión la temperatura elevada y la cizalla fragmenta las moléculas más grandes de los hidratos complejos de carbono en moléculas más pequeñas, que son solubles en agua (29). Los valores encontrados están por debajo de las recomendaciones de consumo de fibra para población adulta de 25 a $30 \mathrm{~g} /$ día según la American Heart Association, de 25 a 35 g/día según los requerimientos establecidos por la FAO/OMS (20), American Dietetic Association y American Health Foundation, sin embargo, el resto de fibra se complementa con la dieta.

Los valores hallados en la digestibilidad in vitro demuestran que varía principalmente por los enlaces peptídicos han sido debilitados por las altas temperaturas, posibilitando una absorción de proteínas, es decir, la facilidad con que es convertido en el aparato digestivo en sustancias útiles para la nutrición y por ende en un indicador de calidad del producto (30), siendo la principal ventaja del proceso de cocción extrusión, el incremento de la digestibilidad proteica (31). La digestibilidad in vitro de la mezcla 3, es superior al reportado en la harina de quinua blanca extruida del ecotipo Jericó con 63.23 y tunkahuan 67.77 (32), 81.66 \% de una mezcla de harina de maíz y frijol lima (33), 79.5 a $81.3 \%$ de una mezcla de cereales y leche fermentada (34).

Los resultados del análisis microbiológico de la mezcla seleccionada, no presentan ningún grado de contaminación, convirtiéndolo en un alimento seguro, demostrándose un proceso inocuo en la operación de cocción - extrusión, además de cumplir con la norma sanitaria para productos cocidos instantáneos RM. 451-2006/MINSA (24), RM 591-2008/MINSA (35) y especificaciones técnicas de harinas instantáneas para alimentos del programa Qaliwarma 2018, programa social que brinda alimentos nutritivos a niños en etapa escolar.

\section{CONCLUSIONES}

De las 25 mezclas alimenticias evaluadas por su calidad proteica mediante score de aminoácidos se seleccionó la mezcla 3 (M3T9) compuesta por 30\% de maca, $25 \%$ quinua, 35 \% cebada y $10 \%$ de arroz; al someter la mezcla seleccionada a un proceso de cocción - extrusión, las propiedades físico-químicas fueron influenciadas por la humedad inicial (10 y $15 \%)$ y temperatura $\left(160-165^{\circ} \mathrm{C}\right)$, el índice de gelatinización fue mayor a medida que aumentaba la temperatura de extrusión, El índice de peróxido fue mayor a una temperatura de $150-155^{\circ} \mathrm{C}$, encontrándose una diferencia proporcional entre la mezcla 1 y 3. El contenido de humedad, grasa, y fibra disminuyeron con el proceso de extrusión, 
mientras el contenido de carbohidratos aumentó. El contenido proteico disminuyó a medida que se aumentaba la temperatura en la cocción - extrusión (7.4 \%), pero incrementó la digestibilidad in vitro $(86 \%)$ y por ende mejoró la biodisponibilidad del nutriente en la mezcla seleccionada.

\section{REFERENCIAS BIBLIOGRÁFICAS}

1. Brownie S. Why are elderly individuals at risk of nutritional deficiency? International Journal of Nursing Practice. 2006; 12.2: 110118

2. Shlisky J, Bloom DE, Beaudreault AR, Tucker KL, Keller HH, Freund-Levi Y, Fielding RA, Cheng FW, Jensen GL, Wu D, Meydani SN. Nutritional considerations for healthy aging and reduction in age-related chronic disease. Advances in Nutrition: An International Review Journal. 2017; 8.1

3. Ramos JM, Suuronen JP, Deegan KC, Serimaa R, Tuorila H, Jouppila K. Physical and sensory characteristics of corn-based extruded snacks containing amaranth, quinoa and kañiwa flour. LWT- Food Science and Technology. 2015; 64.2: 1047-1056

4. Balandrán-Quintana RR, Barbosa-Cánovas GV, Zazueta-Morales JJ, Anzaldúa A, QuinteroRamos A. Functional and nutritional properties of extruded whole pinto bean meal (Phaseolus Vulgaris L.). Journal of Food Science. 2010; 63.1: 113-116

5. Singh S; Gamlath S; Wakeling L. Nutritional aspects of food extrusion:a review. International Journal of Food Science \& Technology 2007; 42: 916- 929

6. Rias MN. Extruders in Food Applications. CRC. 2000; $51-62$

7. Bhattacharya S. Raw materials for extrusión of foods. In: Maskan, M. Altan, A. (Eds.). Advances in Food Extrusion Technology. CRC Press; 2012
8. Xu E, Pan X, Wu Z, Long J, Li J, Xu X, Jin $Z$, Jiao $A$. Response surface methodology for evaluation and optimization of process parameter and 1235 antioxidant capacity of rice flour modified by enzymatic extrusion. Food Chemistry. 2016; 146-154

9. Aluwi NA, Gu BJ, Dhumal GS, MedinaMeza IG, Murphy KM, Ganjyal GM. Impacts of scarification and degermination on the expansion characteristics of select quinoa varieties during extrusion processing. Journal of Food Science. 2016; 81.12: E2939-E2949

10. Abugoch LE, Romero N, Tapi CA, Silva J, Rivera M. Study of some physicochemical and functional properties of quinoa (Chenopodium quinoa Willd) protein isolates. Journal of Agricultural and Food chemistry. 2008; 56.12: 4745-4750

11. Chen L, Li J, Fan L. The Nutritional Composition of Maca in Hypocotyls (Lepidium meyenii Walp.) Cultivated in Different Regions of China. Hindawi Journal of Food Quality. 2017

12. Meissner $\mathrm{HO}, \mathrm{Xu}$ L, Wan W, Yi F. Glucosinolates profiles in Maca phenotypes cultivated in Peru and China (Lepidium peruvianum syn. L. meyenii). Phytochemistry Letters. 2019; 31: 208-216

13. Sifuentes-Penagos $G$, León-Vásquez $S$, Paucar-Menacho LM. Study of Maca (Lepidium meyenii Walp.), Andean crop with therapeutic properties. Scientia Agropecuaria. 2015; 2:131140

14. USDA. Food Composition Database. Food Data Central is an integrated data system that provides expanded nutrient profile data and links to related agricultural and experimental research. 2017

15. Yu L, Li G, Li M, Xu F, Beta T, Bao JS. Genotypic variation in phenolic acids, vitamin $E$ and fatty acids in whole grain rice. Food Chemistry; 2016; 197: 776-782 
16. FAO/OMS/UNU. Necesidades de energía y de proteínas. Reunión Consultiva Conjunta FAO/OMS/UNU de Expertos en Necesidades de Energía y de Proteínas. Serie Inf. Técn. $\mathrm{N}^{\circ}$ 724:220. Roma, Italy; 1991

17. Pellet $P$, Vernon R. Evaluación Nutricional de Alimentos Proteicos. Universidad de las Naciones Unidas; 1980

18. Codex Alimentarius. Standard for processed cereal-based foods for infants and Young child. Codex Stan 74. FAO/OMS; 2019

19. Association of Official Analytical Chemist A.O.A.C. Official methods of the Association for Analytical Chemists. AOAC International; 1990

20. FAO/OMS. Necesidades de Energía y Proteínas. Organización Mundial de la Salud. Ginebra; 1985

21. Baudi, DS. La ciencia de los alimentos en la práctica. Pearson Educación. Impreso en México; 2012

22. Salas, WA. Aplicación del sistema HACCP en el proceso de elaboración de alimentos reconstitución instantánea a base de cereales extruidos. UNMSM; 2003

23. INACAL. Norma Técnica Peruana. Granos andinos. Harina extruida de quinua, requisitos: Perú: NTP 011.457.2016; 2016

24. $R M N^{\circ} 451-2006 / M I N S A$. Diario Oficial El Peruano. Lima, Perú, 13 de mayo de 2006.

25. Codex Alimentarius. Informe de a $15^{\circ}$ reunión del Comité del Codex sobre Grasas y aceites. ALINORM 97/17. Londres, Reino Unido. 1997

26. Amador LN, Moreno V, Martinez-Cordero C. Protein intake, serum lipids and muscle strenght in the elderly. Nutricion Hospitalaria. 2018; 35: 65-70

27. Chicago Dietetic Association y South Suburban Dietetic Association (III) CDA/SSDA. Manual of Clinical Dietetics. 6th. Ed. American Dietetic Association. Chicago, USA. 2000
28. American Dietetic Association y Dietetians of Canada. Position of American Dietetic Association and Dietitians of canada: nutrition and women's health. Journal Am Diet Assoc. 2004; 6.104: 984-1001

29. Ramirez AJL, Wanderlei $P C$, Meléndez AA, Tavares OL, Penteado M. Caracterización fisicoquímica de pellets extruidos de torta de higuerilla (Ricinus comunis l) visando su uso en alimentos balanceados. Embrapa Agroindústria de Alimentos. 2013

30. Manríquez JA. La digestibilidad como criterio de evaluación de alimentos - su aplicación en peces y en la conservación del medio ambiente. En: I Curso Regional de Capacitación. FAO. Control de calidad de insumos y dietas acuícolas. 1993

31. Drago SR, González RJ, Chel-Guerrero L y Valencia M E. Evaluación de la Disponibilidad de Minerales en Harinas de Frijol y en Mezclas de Maíz/Frijol Extrudidas. Revista Información Tecnológica. 2007; 18 (1), 41-46

32. Cerón-Fernandez CL, Guerra-Morcillo LV, Legarda-Quintero JA, Enríquez-Collazos MG, Pismag-Portilla Y. Efecto de la extrusión sobre las características físico-químicas de harina de quinua (Chenopodium quinoa Willd.). Biotecnología en el Sector Agropecuario y Agroindustrial. 2016; 14(2): 92-99

33. Perez-Navarrete C, Betancur-Ancona D, Meris C, Carmona A, Tovar J. Efecto de la extrusión sobre la biodisponibilidad de proteína y almidón en mezclas de harinas de maíz y frijol lima. Arch Lat de Nutr. 2007; 3:57.

34. Ibanoglu $S$, Ainsworth $P$, Hayes GD. In vitro protein digestibility and contento $f$ thiamin and riboflavin in extruded tarhana a traditional turkish cereal food. Food Chemistry. 1997; 1: 141-144

35. RM N $\mathrm{N}^{\circ}$ 591-2008/MINSA. Diario Oficial El Peruano, Lima, Perú, 27 de agosto de 2008 